\title{
KEBIJAKAN PENDIDIKAN KHALIFAH HARUN AR-RASYID
}

\author{
Nilawati Tadjuddin ${ }^{1}$, Alif Maulana ${ }^{2}$ \\ nilawati@radenintan.ac.id \\ ${ }^{1}$ Universitas Islam Negeri Raden Intan Lampung;
}

\begin{abstract}
One of the keys to advancing a nation is education. The future of a nation really needs the contribution of the nation's children who are competitive, superior, intelligent and faithful, given that competition is increasingly high in the global era. Indonesia has several problems in the world of education, starting from the low teacher salaries to high dropout rates, ending with the absence of the Indonesian education system in the list of 20 countries with the best education systems in the world. Islam itself in the field of education had enjoyed periods of glory when the Abbasid dynasty came to power. The fifth caliph's policy, Harun Ar-Rasyid, which at that time concentrated on improving the quality of education, made this period worthy of being dubbed the golden age of Islam (the Islamic Golden Age). The education policy that Ar-Rasyid applied could certainly be a solution to solve various problems that are currently sweeping the world of Indonesian education. This study focuses on the educational policies adopted by Caliph Harun Ar-Rasyid during the golden age of Islam. Through the literature study method, this study confirms that by studying history, all problems that are sweeping the world of education in this country can be resolved, and figures like Ar-Rasyid are the most appropriate to be asked for a solution.
\end{abstract}

Keywords: Harun Ar-Rasyid; Policy; Caliph; Education.

\begin{abstract}
Abstrak
Salah satu kunci untuk memajukan suatu bangsa adalah pendidikan. Masa depan suatu bangsa sangat memerlukan kontribusi anak bangsa yang berkarakter kompetitif, unggul, cerdas, dan beriman, mengingat bahwa semakin tingginya persaingan di era global. Indonesia memiliki beberapa masalah dalam dunia pendidikan, dimulai dari rendahnya gaji guru hingga angka putus sekolah yang tinggi, diakhiri dengan tidak masuknya sistem pendidikan Indonesia dalam daftar 20 negara dengan sistem pendidikan terbaik di dunia. Islam sendiri dalam bidang pendidikan pernah menikmati masa-masa kegemilangannya ketika Dinasti Abbasiyah berkuasa. Kebijakan khalifah kelima yaitu Harun Ar-Rasyid yang saat itu berkonsentrasi meningkatkan mutu pendidikan membuat masa ini layak dijuluki sebagai masa keemasan Islam (the Islamic Golden Age). Kebijakan pendidikan yang Ar-Rasyid terapkan tersebut tentu dapat dijadikan solusi untuk menyelesaikan berbagai problematika yang tengah melanda dunia pendidikan Indonesia saat ini. Kajian ini berfokus pada kebijakan pendidikan yang diterapkan oleh Khalifah Harun Ar-Rasyid pada masa keemasan Islam. Melalui metode studi pustaka, kajian ini menegaskan bahwa dengan mempelajari sejarah, segala permasalahan yang tengah melanda dunia pendidikan di negeri ini dapat terselesaikan, dan sosok seperti Ar-Rasyid paling tepat untuk dimintai solusi.
\end{abstract}

Kata Kunci: Harun Ar-Rasyid; Kebijakan; Khalifah; Pendidikan. 


\section{PENDAHULUAN}

Tercatat bahwa di zaman Harun Ar-Rasyid dan putranya, Al-Ma'mun inilah banyak terjadi gerakan penerjemahan buku-buku dari Yunani, seperti filsafat, kesusastraan, kedokteran, dan lain-lain secara besar-besaran yang disponsori langsung oleh khalifah. Di era itu juga berdirinya suatu lembaga penerjemahan yang termasyhur bernama Bait Al-Hikmah, fungsinya tidak hanya sebagai perpustakaan, tetapi juga sebagai universitas. Semua ini kelak sangat berpengaruh positif dalam berkembangnya ilmu pengetahuan di dunia Islam, juga membawa angin segar bagi masyarakat Eropa Barat (Suwito, 2015).

Ar-Rasyid yang merupakan pemimpin terkuat di dunia pada masa itu, tidak satupun yang mampu menandinginya dalam urusan luas wilayah dan kekuatan pemerintahan serta tingkat kebudayaan dan peradaban yang tinggi dan berkembang di negaranya. Tingkat peradaban dan kekuasaan Khalifah Ar-Rasyid lebih tinggi dan lebih besar jika dibandingkan dengan Karel Agung di Eropa yang menjalin persahabatan dengannya. Baghdad sebagai ibu kota Dinasti Abbasiyah ketika itu tidak ada yang mampu menandingi, bahkan sekalipun dengan Konstantinopel yang merupakan ibu kota Bizantium. Sejak awal berdirinya, Baghdad sudah menjadi pusat kebangkitan ilmu pengetahuan dan peradaban dalam Islam. Atas dasar itulah Philip K. Hitti menyebut Baghdad sebagai kota intelektual, menurutnya Baghdad adalah profesor masyarakat Islam (Amin, 2010).

Ketika Khalifah Ar-Rasyid memerintah, negara berada dalam keadaan makmur, keamanan terjamin, kekayaan melimpah, dan luas wilayah membentang dari India hingga ke Afrika Utara (Amin, 2010). Bait Al-Hikmah merupakan nama dari perpustakaan terbesar yang didirikan oleh Khalifah Ar-Rasyid di awal abad IX Masehi (Yanto, 2015). Fungsi masjid-masjid ketika itu tidak hanya sebagai tempat ibadah tetapi juga tempat untuk belajar (Hitti, 2014).

Ilmu pengetahuan agama berkembang pada masanya, seperti ilmu Al-Qur'an, hadis, qiraat, bahasa dan sastra, ilmu kalam, dan fikih. Empat mazhab fikih juga tumbuh dan mengalamai perkembangan pada masa Ar-Rasyid. Selain ilmu di atas berkembang pula berbagai disiplin ilmu lain, seperti ilmu filsafat, logika, matematika, aritmatika, aljabar, mekanika, metafisika, kimia, astronomi, geografi, ilmu alam, dan kedokteran (Amin, 2010). 
Berdasarkan penelitian terdahulu, telah dilakukan penelitian yang membahas tentang kebijakan (Budiharjo, 2013; Fathurrahman, 2018; Israil, 2011; Khairuddin, 2011; Mubarak, 2009; Nurhakim, 2017; Rahmawati, 2008; Ridlo, 2013; Sari, 2015) pada masa kekhalifahan (Faidi, 2018; Harimurti, 2015; Yusuf, 2012) dan beberapa peneliti sebelumnya membahas tentang pendidikan islam (Ainissyifa, 2014; Amaliyah, 2013; Mahroes, 2015; Maryamah, 2015; Rajab, 2014; W. Setiawan, 2018; Suriana, 2017; Suyuthi, 2011; Syah, 2008; Wahyuningsih, 2014; Wasito, 2015) serta berhubungan dengan Harun Ar-Rasyid (Anshori, 2015; Ismiyati \& Umamah, 2015; Nasution, 2017). Namun, belum ada penelitian sebelumnya yang mempelajari kebijakan-kebijakan pendidikan pada masa Harun Ar-Rasyid pada masa kejayaan islam dahulu, sebagai rujukan untuk menyelesaikan berbagai problematika yang melanda dunia pendidikan Indonesia saat ini. Maka, tujuan penelitian ini adalah untuk menganalisa kebijakan pendidikan yang tertuang dalam buku-buku yang membahas Khalifah Harun Ar-Rasyid, sehingga dari analisis tersebut dapat ditemukan jawaban dari masalah yang diteliti, yaitu kebijakan pendidikan Khalifah Harun Ar-Rasyid.

\section{HASIL KAJIAN DAN PEMBAHASAN}

Harun Ar-Rasyid bernama lengkap Harun Abu Ja'far bin Al-Mahdi Muhammad bin Al-Manshur Abdillah bin Muhammad bin 'Ali bin Abdillah bin Abbas. Beliau menjadi khalifah dengan penunjukkan dari ayahnya sepeninggal saudaranya Musa AlHadi pada malam Sabtu, 14 Rabi’ul Awwal 170 H (As-Suyuthi, 2015).

Beliau adalah khalifah kelima Dinasti Abbasiyah sekaligus yang paling terkenal. Ar-Rasyid dilahirkan pada tahun 145 H di Rayy. Ibundanya bernama Al-Khizran, seorang Uтmи Walad, sedangkan ayahnya merupakan khalifah ketiga Dinasti Abbasiyah, Muhammad Al-Mahdi. Menjelang dewasa, sang ayah mempersiapkan ArRasyid sebagai seorang khalifah. Karena itu, Al-Mahdi melimpahkan tugas dan tanggung jawab besar kepadanya. Al-Mahdi dua kali mengangkat Ar-Rasyid sebagai komandan militer di Ash-Sha'ifah, yakni pada tahun 163 dan $165 \mathrm{H}$. Pada tahun $164 \mathrm{H}$, Al-Mahdi mengangkatnya sebagai walikota wilayah Barat secara keseluruhan mulai dari Anbar hingga seluruh perbatasan Afrika. Para pemimpin daerah pun banyak dikirim dan diangkat olehnya (Al-Khudhari, 2016). 
Khalifah Harun Ar-Rasyid merupakan seorang pemimpin yang peduli menjaga dan melestarikan syariat atau hukum-hukum Allah dengan sebaik-baiknya. Adapun mengenai salatnya, salat sunnah seratus rakaat biasa ia kerjakan setiap harinya hingga wafat, kecuali jika sedang menderita sakit. Khalifah Ar-Rasyid memiliki kawan diskusi bernama Ibnu Abu Maryam Al-Madani, di mana Khalifah tidak bisa berjauhan dan tidak bosan berbincang dengannya. Khalifah Ar-Rasyid pernah berpesan kepadanya, "Takutlah kamu terhadap Al-Qur'an dan agama, dan kamu boleh melakukan apa saja selain daripada keduanya." (Al-Khudhari, 2016).

Ar-Rasyid wafat ketika sedang memimpin pasukannya menuju menuju Khurasan. Saat mencapai kota Thus pada bulan Shafar tahun 193 H, di sanalah penyakitnya kambuh hingga mengantarkannya pada Rabbnya, pada malam Sabtu, 22 Jumadil Akhir tahun 193 H (Al-Khudhari, 2016).

Khalifah Harun Ar-Rasyid adalah seorang pemimpin yang mencintai para ulama. Ia mengagungkan dan memuliakan agama serta membenci omong kosong dan debat. Al-Qadhi Al-Fadhil berkata di dalam risalahnya: "Aku tidak pernah mengetahui sama sekali jika seorang raja memiliki perjalanan ilmiah, kecuali Ar-Rasyid. Sesungguhnya dia pergi bersama kedua putranya, Al-Amin dan Al-Ma'mun untuk mendengarkan kitab Al-Muwatha' dari Imam Malik rahimahullah.” Al-Qadhi Al-Fadhil melanjutkan, "Naskah asli Al-Muwatha' hasil pendengaran Ar-Rasyid berada di gudang penyimpanan penduduk Mesir.” (As-Suyuthi, 2015).

Khalifah Harun Ar-Rasyid sangat menjamin kesejahteraan hidup para guru. Ketika sekolah-sekolah didirikan, maka ditentukan guru-guru yang akan mengajar serta gaji bulanan yang diatur oleh bendahara umum. Gaji ini juga diperoleh dari badanbadan wakaf yang digunakan untuk memberikan infak untuk urusan tersebut. Gaji yang diberikan berbeda-beda menurut kedudukan pengajar atau masukan wakaf, meskipun begitu masih cenderung mewah dan cukup banyak. Di antara pengajar itu adalah AzZajaj yang mendapatkan rizki sebanyak dua ratus dinar setiap bulan sebagai fuqaha dan ulama. Begitu juga dengan Hakim Al-Muqtadir bin Daraid yang mendapatkan lima puluh dinar pada setiap bulannya, padahal ia datang ke Baghdad dalam keadaan miskin (As-Sirjani, 2011).

Khalifah Ar-Rasyid memerintahkan untuk membangun perpustakaanperpustakaan agar minat baca rakyatnya dapat difasiltasi di seluruh wilayah Abbasiyah, 
tidak hanya di Baghdad. Dari berbagai perpustakaan keemasan Islam itu, yang amat terkenal adalah Bait Al-Hikmah. Bait Al-Hikmah atau Rumah Kebijaksanaan (House of Wisdom) adalah perpustakaan sekaligus lembaga pendidikan Islam pertama yang ArRasyid bangun di ibu kota negara, Baghdad. Fungsi Bait Al-Hikmah tidak hanya sebagai sebuah perpustakaan ataupun gudang buku, tapi Bait Al-Hikmah juga memiliki biro penerjemahan serta tempat berkumpulnya para intelektual dan cendikiawan dari berbagai penjuru kerajaan (Lyons, 2013; Salahudin, 2011; Yanto, 2015).

Pada intinya, fungsi utama Bait Al-Hikmah adalah sebagai pusat pelestarian pengetahuan yang tak ternilai harganya, sebuah fakta yang tercermin dalam istilahistilah para sejarawan Arab ketika itu untuk menggambarkan proyek tersebut, seperti Perbendaharaan Buku-buku Kebijaksanaan atau Perbendaharaan Kebijaksanaan. Para ahli yang bergabung dengan lembaga kerajaan ini tak jarang menjadi staf observatorium sang khalifah dan juga turut serta dalam eksperimen-eksperimen ilmiah yang diperintahkannya. Bait Al-Hikmah juga memainkan peranan penting dalam pengembangan karya-karya kesusastraan Abbasiyah (Lyons, 2013).

Bait Al-Hikmah merupakan simbol dari kehidupan manusia yang memiliki kecerdasan intelektual dan berperadaban tinggi. Karena penguasaan terhadap ilmu pengetahuan dapat merasuki sendi-sendi kehidupan manusia yang paling dalam, yaitu ruang akal dan pemikiran, dan memberikan efek yang lebih besar dari sekedar penguasaan jasmani belaka. Bait Al-Hikmah hancur bersamaan dengan runtuhnya Dinasti Abbasiyah akibat serangan bangsa orang-orang Tartar (Mongol) pimpinan Hulaghu Khan, cucu dari Genghis Khan (Hitti, 2014).

Sayangnya, sangat sedikit karangan ilmiah yang dapat diselamatkan dari kehancuran tersebut. Adapun buku-buku yang berhasil diselamatkan, kemudian diakui oleh banyak kalangan ilmuwan Barat sebagai temuan mereka. Temuan tersebut menjadi sebab penting dalam pergerakan ilmiah modern di Eropa. Oleh karena itu, Bait AlHikmah layak dikatakan sangat berperan besar dalam peradaban manusia, di mana temuannya menjadi sarana penting dari temuan-temuan pada masa sekarang (As-Sirjani, 2011).

Khalifah Ar-Rasyid juga menerjemahkan buku-buku pengetahuan ke dalam bahasa arab. Gerakan penerjemahan merupakan bentuk dari asimilasi yang terjadi antara bangsa Arab dengan bangsa-bangsa lainnya yang telah terlebih dahulu mengalami 
perkembangan dalam bidang ilmu pengetahuan. Penyebabnya adalah karena banyaknya bangsa-bangsa non-Arab yang mulai masuk Islam pada masa Abbasiyah (Yatim, 2016). Buku-buku yang diterjemahkan di antaranya adalah buku-buku ilmu pengetahuan berbahasa Persia, Sansekerta, Suriah, dan Yunani (Hitti, 2014). Pengaruh Yunani terlihat melalui berbagai terjemahan dalam bidang ilmu, khususnya filsafat. Pengaruh India sangat terlihat pada bidang kedokteran, ilmu matematika, dan astronomi. Sedangkan pengaruh Persia sangat kuat dalam bidang pemerintahan, filsafat, dan sastra (Yatim, 2016).

Proyek penerjemahan ini juga disebut sebagai gerakan intelektual dalam sejarah Islam, sehingga dikenal sebagai kebangkitan terkenal dalam seluruh sejarah pemikiran dan budaya. Peradaban Yunani memang cukup memberikan pengaruhnya, dalam tempo tiga perempat abad setelah berdirinya Baghdad, dunia literatur Arab telah memiliki karya para komentator neo-Platonis, filsafat utama karya Aristoteles, dan tulisan-tulisan kedokteran Galen (Hitti, 2014). Al-Khawarizmi adalah satu dari sekian tokoh ilmuwan yang terbantu dengan kebijakan Ar-Rasyid ini. Ia menyusun karya besarnya, Surah AlArdh (Gambar/Peta Bumi) dengan mengacu pada Geography, buku karya ilmuwan Yunani, Ptolemius yang sudah diterjemahkan ke dalam bahasa Arab (Hitti, 2014).

Era penulisan karya-karya orisinal juga mengiringi era penerjemahan yang produktif dan cukup panjang di awal masa Dinasti Abbasiyah. Pada abad ke-10, bahasa Arab, yang pada masa pra-Islam merupakan satu-satunya bahasa syair, dan pada masa Rasulullah menjadi bahasa wahyu dan agama, telah berkembang dengan cara yang menakjubkan, dan tiada bandingnya dalam sejarah, menjadi media yang terbukti sanggup bertindak sebagai sarana untuk mengekspresikan pemikiran ilmiah serta menampung gagasan filosofis tingkat tinggi. Sementara itu, bahasa Arab telah mengukuhkan dirinya sebagai bahasa percakapan dan bahasa diplomasi di berbagai wilayah, mulai dari Asia Tengah, membentang ke Afrika Utara hingga mencapai Spanyol. Sejak saat itu, bangsa-bangsa yang bermukim di Irak, Suriah, Palestina, Mesir, Tunisia, Aljazair, hingga Maroko telah mengungkapkan pemikiran terbaik mereka dalam bahasa Arab (Hitti, 2014).

Pada masa dinasti Abbasiyah, pendidikan dan pengajaran berkembang dengan sangat pesat sehingga anak-anak bahkan orang dewasa berlomba-lomba menuntut ilmu pengetahuan, melawat ke pusat-pusat pendidikan meninggalkan kampung halaman 
mereka, demi untuk mendapatkan ilmu pengetahuan. Dan salah satu indikator berkembang pesatnya pendidikan dan pengajaran ditandai dengan berkembang luasnya lembaga-lembaga pendidikan Islam (Maryamah, 2015).

Dalam dunia Islam sebelum munculnya lembaga pendidikan formal, masjid dijadikan sebagai pusat pendidikan selain untuk tempat menunaikan ibadah. Hubungan sejarah pendidikan masyarakat Islam dengan masjid merupakan hubungan yang erat sekali. Sebab, masjid merupakan pusat peradaban Islam yang berfungsi tidak hanya sebagai pusat keagamaan, tetapi masjid merupakan salah satu tempat yang sangat penting dalam pendidikan Islam (As-Sirjani, 2011).

Begitu pula yang terjadi di Masjid Damaskus yang merupakan pusat yang sangat penting dari pusat-pusat peradaban dan dijadikan sebagai halaqah-halaqah keilmuan. Di dalam masjid juga terdapat beberapa tempat yang dijadikan para penuntut ilmu untuk menasakh dan belajar, sebagaimana yang dilakukan Al-Khatib Al-Baghdadi yang mempunyai halaqah besar yang memberikan beberapa pelajaran ilmu, sebagai tempat orang-orang berkumpul setiap hari (As-Sirjani, 2011).

Para sahabat juga mempunyai halaqah ilmu di dalam Masjid Nabawi, sebagaimana dikisahkan oleh Makhul dari seorang laki-laki, bahwasannya dia bercerita, "Kami duduk di halaqah 'Umar bin Khaththab radhiallahu 'anhu di Masjid Madinah mengingat keutamaan-keutamaan Al-Qur'an, lalu membicarakan hadis tentang keistimewaan Bismillahirrahmanirrahim." Sahabat mulia Abu Hurairah radhiallahu 'anhu mempunyai halaqah di Masjid Nabawi, mengajarkan hadis-hadis Nabi shallallahu 'alaihi wasallam di mana halaqah ini berlainan waktu dengan halaqah menghapal beliau yang membahas kelembutan dan kejujuran Rasulullah shalallahu 'alaihi wasallam. Tidak hanya Abu Hurairah, halaqah lain yang terkenal di Masjid Nabawi adalah halaqah sahabat mulia Jabir bin Abdillah radhiallahu 'anhu (As-Sirjani, 2011).

Di Masjid Baghdad sendiri terdapat lebih dari empat puluh halaqah. Semua halaqah itu diringkas menjadi satu dalam halaqah Imam Syafi'i rahimahullah karena ilmunya yang mulia. Seorang ahli bahasa bernama Al-Zajaj yang meriwayatkan kisah ini. Dia mengatakan, "Ketika Imam Syafi'i datang ke Baghdad, saat itu di masjid terdapat hampir 40 sampai 50 halaqah. Ketika dia memasuki Baghdad, mereka duduk di halaqah-halaqah. Imam Syafi'i berkata, "Allah berfirman, Rasulullah bersabda." 
Sedangkan di halaqah lain mereka mengatakan, "Sahabat kami berkata." Akhirnya tidak tersisa dalam masjid selain halaqahnya (As-Sirjani, 2011).

Masjid juga memiliki fungsi sebagai tempat penyimpanan buku atau perpustakaan. Buku-buku itu didapatkan dari hadiah-hadiah yang diserahkan kepada pengurus masjid maupun hasil pencarian dari berbagai sumber. Karenanya, khazanah buku-buku keagamaan di masjid-masjid pada masa itu sangat kaya. Al-Khathib AlBaghdadi (1002-1071 M) merupakan salah seorang donatur dari buku-buku itu. Beliau menyerahkan buku-bukunya sebagai wakaf untuk umat Islam (Hitti, 2014).

Pada masa pemerintahan Dinasti Abbasiyah, masjid boleh dikatakan sebagai lembaga pendidikan Islam yang khas, dan pemerintah sangat mendukung penyelenggaraan pendidikan di masjid, seperti Khalifah Harun Ar-Rasyid yang kemudian diteruskan oleh khalifah sesudahnya. Pada abad pertama, Islam tersebar di mana saja dengan perkembangannya yang luar biasa. Tradisi masjid sebagai pusat peribadatan juga menyertainya. Dengan demikian, wajar saja apabila para Khalifah Abbasiyah sedikit demi sedikit memandang bahwa urgensi masjid tidak hanya sebagai tempat peribadatan, melainkan juga sabagai pusat pengajaran bagi kaum muda (Suwito, 2015).

Bila masa anak-anak tersebut dimanfaatkan dengan baik, harapan di masa selanjutnya akan mudah diraih. Oleh karena itu, para ulama berkata, "Anak adalah amanah bagi kedua orangtuanya. Hatinya yang masih suci bagaikan permata yang murni. Bebas dari segala macam ukiran dan lukisan. Ia siap menerima segala bentuk pahatan dan cenderung kepada apa saja yang ditanamkan kepadanya. Bila ia dibiasakan untuk melakukan kebaikan, ia pasti tumbuh menjadi orang yang baik. Kedua orangtua akan mendapatkan kebahagiaan dunia dan akhirat, termasuk guru dan pembimbingnya. Namun, bila ia dibiarkan melakukan hal-hal yang buruk dan ditelantarkan tanpa pendidikan dan pengajaran, ia pasti akan menjadi orang yang celaka dan binasa. Dengan begitu, orang yang bertanggung jawab atasnya dan juga walinya akan menanggung dosanya." (Abdurrahman, 2010).

Mari kita simak nasihat Nabi shallallahu 'alaihi wasallam kepada Abdullah bin Abbas radhiallahu 'anhuma yang masih berusia kecil berikut ini, sebuah pembicaran tingkat tinggi dengan seorang anak kecil. 


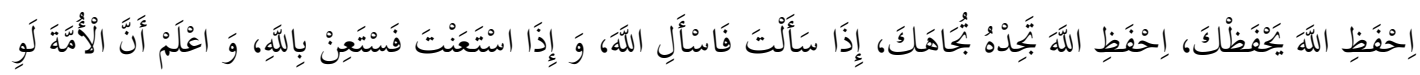

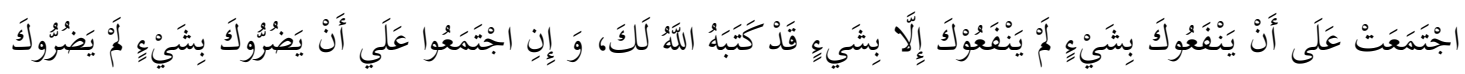

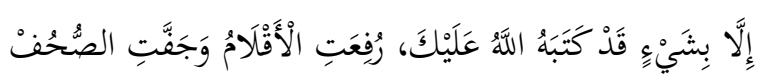

Artinya : Jagalah Allah, maka ia akan menjagamu. Jagalah Allah, maka kamu akan mendapati-Nya ada di hadapanmu. Jika kamu meminta, mintalah kepada Allah. Dan jika kamu meminta pertolongan, mintalah pertolongan kepada Allah. Ketauhilah nak, jika seluruh umat ini bersatu untuk memberikanmu manfaat, maka manfaat itu tidak akan pernah menjadi milikmu kecuali Allah sudah menakdirkannya untukmu. Dan jika seluruh umat ini bersatu untuk mencelakakanmu, mereka juga tidak akan pernah sanggup mencelakakanmu kecuali itu sudah takdirmu. Pena telah diangkat dan lembaran-lembaran telah kering. [dari Ibnu Abbas radhiallahu 'anhuma, H.R. At-Tirmidzi, dia berkata: hadis ini hasan shahih]

Dalam riwayat lain ada tambahan,

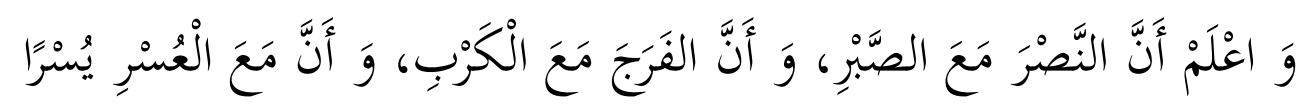

Artinya : Ketahuilah nak, sesungguhnya pertolongan datang bersama kesabaran, kelapangan datang bersama kesempitan, dan bersama kesulitan itu pasti ada kemudahan (An-Nawawi, 2017).

Tentunya, mendidik dan mengajar anak bukan termasuk perkara yang mudah dan tidak bisa dilakukan sambil lalu. Mendidik dan mengajar anak merupakan kewajiban dan kebutuhan pokok yang harus dipenuhi oleh semua orangtua. Firman Allah:

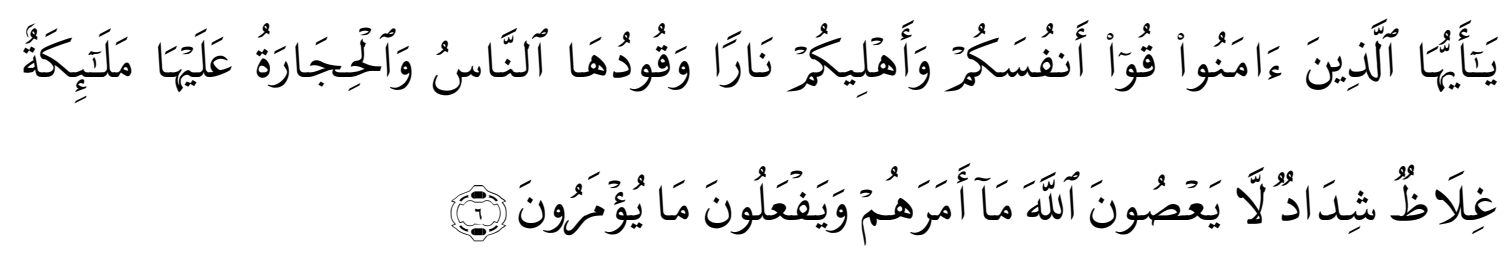

Artinya: Wahai orang-orang yang beriman! Peliharalah dirimu dan keluargmu dari api neraka yang bahan bakarnya manusia dan batu; penjaganya adalah malaikat-malaikat yang kasar, dan keras, yang tidak durhaka kepada Allah terhadap apa yang Dia perintahlan kepada mereka dan selalu mengerjakan apa yang diperintahkan [Q.S. At-Tahrim : 6].

Saat menafsirkan ayat ini, 'Ali bin Abi Thalib radhiallahu 'anhu mengatakan, "Didiklah dan ajarilah mereka." Mengajar, mengarahkan, dan mendidik anak tak ubahnya usaha mendapatkan surga. Mengabaikan semua itu berarti neraka. Dengan demikian, tidak ada lagi celah untuk menyia-nyiakan tugas ini. Mendidik dan mengajari 
anak merupakan suatu kewajiban. Nabi shallallahu 'alaihi wasallam bersabda: Ajarilah (anak-anak kalian). Mudahkanlah dan jangan dipersulit.” [H.R. Ahmad] (Abdurrahman, 2010).

Sebagai seorang ayah, Harun Ar-Rasyid sangat tegas mendidik putranya. Sejak Al-Ma'mun masih kecil, Ar-Rasyid sendiri yang membimbingnya menghafalkan ayatayat suci Al-Qur'an. Menghafalkan Al-Qur'an sepertinya merangsang intelektualitas Al-Ma'mun dan rasa ingin tahunya. Calon Khalifah ketujuh Dinasti Abbasiyah ini merupakan seorang murid yang tekun, sifat yang selalu dicoba ditanamkan oleh ayahnya sejak awal. "Jangan biarkan dia bosan atau kelelahan. Jangan memudahkannya dan jangan biarkan dirinya bermalas-malasan," konon seperti itu perintah Ar-Rasyid kepada guru putranya tersebut (Lyons, 2013).

Mendidik dan mengajar merupakan hadiah terbaik dan perhiasan terindah yang diberikan orangtua kepada anaknya. Nilainya lebih baik dari dunia dan seisinya. Orangorang yang ikhlas hendaknya menyingsingkan lengan baju dan bekerja dengan tekun dan tulus untuk membentuk generasi yang sesuai dengan generasi yang telah dididik oleh Nabi Muhammad shallallahu 'alaihi wasallam, dan hal ini tidak mungkin akan terwujud tanpa mengikuti metode pendidikan yang telah beliau terapkan (Abdurrahman, 2010).

Ketika Khalifah Harun Ar-Rasyid memimpin, sekolah dasar (kuttab) berkurikulum utamanya dipusatkan pada Qur'an sebagai bacaan utama para siswa, dan diajari keterampilan baca-tulis dengan rujukan dari syair-syair Arab tempo dulu. Hampir seluruh kurikulum yang diaplikasikan pada masa itu adalah metode menghafal yang sangat dipentingkan (Hitti, 2014).

Dalam bidang sains, Al-Qur'an telah menjadi inspirasi bagi muslimin untuk meneliti ayat demi ayat hingga melahirkan suatu penemuan baru. Dalam bidang astronomi atau ilmu falak, yang menurut kaum Muslimin berkaitan erat dengan syiar agama, timbulah kebutuhan untuk memperlajarinya guna menentukan waktu-waktu salat sesuai kondisi letak geografis dan perubahan musim. Begitu pula untuk penentuan arah kiblat, gerakan bulan untuk menentukan awal Ramadhan, haji dan sebagainya (AsSirjani, 2011).

Semua ini terdapat dalam ayat Al-Qur'an yang begitu memerhatikan ilmu astronomi dan alam semesta untuk kebutuhan manusia dengan segala karunia-Nya. Di 
samping itu, muslimin juga dianjurkan untuk merenungi kejadian langit dan bumi, sebagaimana disebutkan dalam Al-Qur'an surat Yasin ayat 37-40, atau surat Yunus ayat $5-6$.

Al-Qur'an juga menyerukan hal yang lebih dari itu, menyebutkan bintangbintang tertentu dengan nama-namanya. Firman Allah,

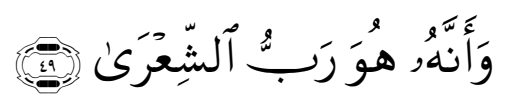

Artinya : dan bahwasanya Dialah Tuhan (yang memiliki) bintang Syi'ra [Q.S. An-Najm 49]

Semua ayat suci Al-Qur'an itu menghadirkan fakta ilmiah yang mustahil orang sanggup memahaminya atau sekedar mencoba menafsirkannya selagi tidak mempunyai atau menguasai ilmu yang luas tentang ilmu falak (As-Sirjani, 2011).

Sebuah pernyataan bernada menggugat datang dari Guru Besar Universitas Kairo, Syekh Jauhari Thantawi. Dalam tafsirnya, Al-Jawahir, Syekh Thantawi menulis bahwa di dalam Kitab Suci Al-Qur'an terdapat lebih dari 750 ayat kauniah, yaitu ayat yang berbicara tentang alam semesta, dan hanya 150 ayat fikih. Anehnya, ribuan kitab fikih telah ditulis oleh para ulama, tetapi mereka nyaris tidak mengamati serta menulis kitab tentang alam semesta dan isinya. Umat dan para ulama banyak menghabiskan waktu untuk membahas persoalan fikih, dan sering kali bertengkar karenanya. Tetapi mereka mengabaikan fenomena terbitnya matahari, gerak edar bulan, dan kelapkelipnya bintang. Mereka lalai atas gerak awan di langit, listrik yang membakar, kilat yang menyambar, mutiara yang gemerlap dan malam yang gelap gulita. Mereka juga tak tertarik pada aneka tumbuhan di sekitarnya, binatang ternak, maupun binatang buas yang bertebaran di muka bumi, dan aneka fenomena serta keajaiban lainnya.

Perhatian negara-negara Islam terhadap ilmu pengetahuan (sains) dan perkembangannya masih sangat rendah. Science Citation Index 2004 memberikan data bahwa total 46 negara Islam hanya memberikan kontribusi sebanyak 1,17 persen terhadap penerbitan karya ilmiah dunia. Nilai tersebut masih lebih rendah jika dibandingkan dengan sumbangan satu negara, seperti India dan Spanyol, yang masingmasing menyumbang 1,16 persen dan 1,48 persen. 20 negara Arab bahkan hanya menyumbang 0,55 persen dari total karya ilmiah dunia, sedangkan Israel sendiri mampu menyumbang 0,89 persen. Sementara developed countries (negara-negara maju) seperti 
Jerman, Inggris, atau Jepang, berurutan menyumbang 7,1 persen, 7,9 persen, dan 8,2 persen, bahkan Amerika mencapai 30,8 persen.

Masalah tersebut terkait dengan anggaran yang disediakan untuk kepentingan pengembangan sains dan teknologi, termasuk kegiatan riset dan pengembangan serta dukungan atas aktivitas ilmiah lainnya. Anggaran belanja yang dialokasikan oleh negara-negara Islam hanya sebanyak 0,45 persen GNP, sedangkan dana yang dihabiskan oleh negara-negara maju yang terdaftar dalam Organization for Economic Cooperation and Development (OECD) adalah sebanyak 2,30 persen dari GNP untuk keperluan yang sama. Sumber daya manusia untuk mendukung kegiatan riset dan pengembangan di negara-negara Islam juga terbatas. Secara rata-rata, negara-negara Islam memiliki 8,8 ilmuwan, insinyur, dan teknisi per 1.000 penduduk dibandingkan dengan negara-negara OECD yang memiliki 139,3 atau 40,7 di negara-negara maju di luar OECD.

Angka-angka terakhir yang juga kurang menggembirakan ini diperparah oleh kenyataan lain, yaitu terjadinya migrasi tenaga ahli (brain drain) ke negara-negara maju. Dalam tiga dekade terakhir, lebih dari 500 ribu ilmuwan dari negara-negara Dunia Ketiga bermigrasi ke Eropa, Amerika, Kanada, dan Australia. Sebanyak 55 persen berasal dari Asia. Iran, Pakistan, dan Turki adalah tiga negara Islam kawasan Asia yang mayoritas kehilangan ilmuwan akibat brain drain ini. Hal yang sama dialami Mesir, Aljazair, serta Maroko yang memiliki kawasan Afrika. Demikian pula Suriah, Lebanon, dan Yordania yang menjadi representasi negara Arab. Dua ilmuwan muslim terkemuka, Dr. Abdus Salam dan Dr. Ahmed Zewail, masing-masing meraih nobel bidang fisika dan kimia setelah hijrah dari Pakistan ke Inggris dan dari Mesir ke Amerika. Mereka sebagai ilmuwan tidak tumbuh dan berkembang di negerinya sendiri, tetapi di negara Barat (Purwanto, 2015).

Al-Qur'an selalu memotivasi manusia agar belajar, berpikir, dan meneliti alam semesta. Motivasi itu tidak semata-mata untuk kepentingan penambahan ilmu pengetahuan saja, tetapi yang terpenting adalah membangun kesadaran individu sebagai hamba Allah. Itulah sebabnya Al-Qur'an dalam setiap perbincangannya mengenai fenomena alam selalu dihubungkan dengan keimanan. Perbincangan itu lebih merupakan penanaman iman dan kesadaran diri sebagai makhluk ciptaan Tuhan dengan menggunakan alam sebagai media perbincangan. Selain itu perbincangan tersebut juga 
bertujuan untuk memotivasi manusia agar mengkaji alam sekitarnya, dan temuan kajian terhadap alam diharapkan dapat menambah tingkat keimanan seseorang. Nabi shallallahu 'alaihi wasallam bersabda yang diriwayatkan dari Ibnu Mas'ud radhiallahu 'anhu: Barangsiapa menginginkan ilmu, hendaklah ia menyelami makna-makna AlQur'an. Sesungguhnya pada Al-Qur'an itu terdapat ilmu-ilmu bagi umat manusia [H.R. Tabrani].

Mengutamakan Ta'dib dalam pendidikan itu sangat penting. Ta'dib berasal dari kata addaba, yuaddibu, ta'dib, yang berarti adab, atau mendidik manusia menjadi beradab. Ta'dib adalah istilah yang paling mewakili dari makna pendidikan berdasarkan Al-Qur'an dan hadis Nabi shallallahu 'alaihi wasallam, sebagaimana yang dikemukakan oleh Syed Muhammad Naquib Al-Attas. Beliau memaknai pendidikan berdasarkan hadis Nabi shallallahu 'alaihi wasallam:

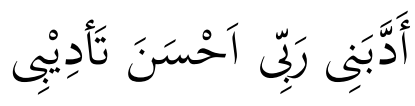

Artinya : "Tuhanku telah mendidikku, maka Dia menjadikan pendidikanku yang terbaik.” (Syah, 2008).

Pendidikan, menurut Al-Attas adalah penyemaian dan penanaman adab dalam diri seseorang, inilah yang disebut dengan ta'dib. Tujuan dari pendidikan bukanlah untuk menghasilkan pekerja dan warga negara yang baik, tetapi untuk menciptakan sosok manusia yang baik (Suyuthi, 2011).

Mari kita cermati wasiat Ar-Rasyid kepada Ahmar, guru bagi putra mahkotanya Muhammad Al-Amin berikut ini:

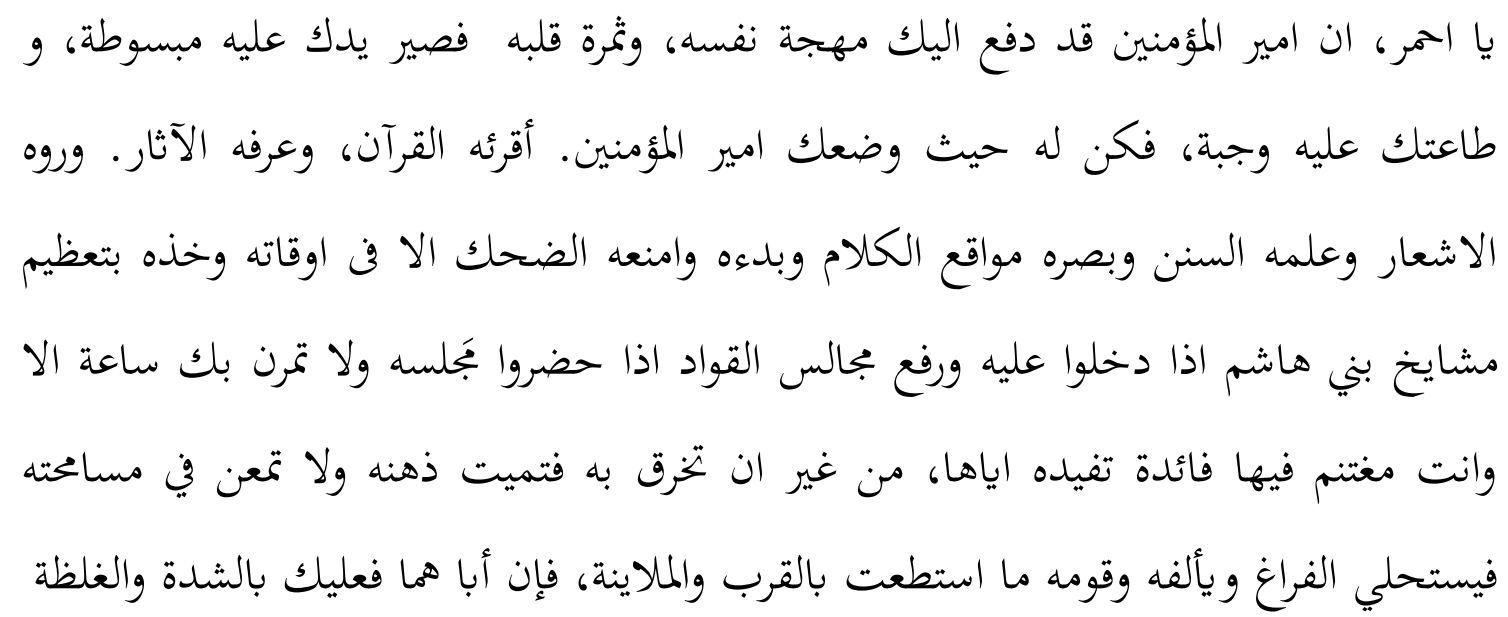

Artinya : Wahai Ahmar, saat ini Amirul Muminin telah memasrahkan kepadamu buah hatinya. Maka bukalah kedua tanganmu untuk menyambutnya, dan dia 
wajib menaatimu. Maka posisikanlah dirimu sebagaimana engkau telah dipercaya oleh Amirul Mukminin. Ajarkan padanya cara membaca Al-Quran, kenalkan padanya hadis Nabi Muhammad shallallahu 'alaihi wasallam, bacakan padanya tentang sya'ir, kenalkan padanya tuntunan sunnah Rasul shallallahu 'alaihi wasallam, serta ajarkan padanya keterampilan retorika. Tuntunlah ia agar tidak tertawa kecuali pada saat yang tepat. Tuntunlah ia untuk menghormati keluarga besar Bani Hasyim jika mereka sedang datang ke istana, serta ajarilah ia untuk menghormati pasukan tentara kerajaan. Janganlah engkau lengah sedikitpun dalam mendidiknya, serta jangan menggunakan kekerasan karena itu akan mematikan hati dan perasaannya. Tetapi di sisi lain, janganlah engkau terlalu permisif sehingga dia merasa nyaman membuang-buang waktu. Jika engkau ingin meluruskannya atas dasar suatu perkara, dekatilah ia dengan lemah lembut. Jika cara ini tidak diindahkan olehnya, maka kamu berhak mengingatkannya dengan cara yang keras (Anshori, 2015).

Tongkat kecil dianggap sebagai perangkat penting yang mesti dimiliki oleh seorang guru, dan telah disetujui oleh khalifah untuk digunakan pada anak-anak. Ibnu Sina dalam bukunya yang berjudul Risalah as-Siyasah pada bab manajemen pendidikan anak, berbicara tentang tongkat sebagai bagian penting dari seni mengajar yang tentu harus dimiliki oleh seorang pendidik (Hitti, 2014).

Muhammad Al-Fatih adalah sebuah nama yang seharusnya menjadi inspirasi besar bagi kehidupan kaum Muslimin hari ini. Betapa tidak, nama ini melekat kuat pada sebuah sejarah besar peradaban Islam yang jauh-jauh hari telah dikabarkan oleh Rasulullah shallallahu 'alaihi wasallam. Sekitar 800 tahun, jauh sebelum Muhammad Al-Fatih lahir. Dalam hadis yang diriwayatkan oleh Ahmad dishahihkan oleh AlHakim, Adz-Dzahabi dan Al-Albani, Rasulullah shallallahu 'alaihi wasallam menjanjikan bahwa dua kota besar umat Nasrani, Konstantinopel dan Roma akan jatuh ke tangan muslimin, dan Konstantinopel yang akan dibuka lebih dulu.Janji Rasulullah shallallahu 'alaihi wasallam ini disampaikan pada saat peristiwa Perang Khandaq, sekitar tahun 5 Hijriah atau 627 M. Janji ini menjadi kenyataan delapan abad kemudian pada tahun $857 \mathrm{H}$ atau $1453 \mathrm{M}$, setelah Konstantinopel dibuka oleh Al-Fatih (Ashari, 2013).

Sesungguhnya Al-Fatih bukanlah seorang anak yang dapat dikatakan istimewa sejak kecil. Sikap Al-Fatih kecil yang enggan belajar dikeluhkan oleh ayahnya, Sultan Murad II. Terlahir sebagai seorang anak bangsawan yang menyandang predikat sebagai putra mahkota ternyata membuat dirinya merasa bisa bersikap sekehendaknya. Al-Fatih 
kecil merasa tak seorang pun berani melarangnya. Guru silih berganti, namun tak kunjung ada yang berhasil.

Hal ini dapat dicermati oleh Sultan Murad II, sang ayah. Di tengah kebingungan itulah sultan mendapatkan informasi tentang seorang ulama faqih dan bijak yang bernama Ahmad bin Ismail Al-Kurani. Ulama ini kemudian dipanggil ke istana oleh sultan. Setelah bertemu, sultan pun menyampaikan perihal anaknya dan berbagai keluhan kesulitan belajar yang terjadi pada Al-Fatih kecil. Sang guru menyimak dengan seksama keluhan sultan. Di akhir pembicaraan, sultan menyerahkan satu pemukul kecil kepada sang guru untuk dipergunakan seandainya Al-Fatih tidak mau mendengarkan dan mengikuti perintahnya. Sang guru berusaha menghormati permintaan sekaligus usulan sultan tadi.

Tibalah hari pertama Syekh Ahmad mengajar Al-Fatih. Benar saja, Al-Fatih bertindak semaunya. Tidak ada penghargaan sedikit pun pada sang guru. Muhammad kecil itu malah menertawakan Syekh Ahmad. Maka sesuai amanah ayahnya, sabetan sang guru adalah pelajaran pertama yang ia dapatkan hari itu.

Teguran itu membuat Al-Fatih terkejut. Benar-benar di luar dugaannya. Selama ini ia mengira tidak ada satu guru pun yang berani bersikap demikian kepadanya. Setelah kejadian itu, Al-Fatih kecil selalu menuruti setiap perkataan oleh sang guru. AlFatih pun belajar dengan tekun terhadap setiap ilmu yang disampaikan kepadanya. Syekh Ahmad berhasil menekuk jiwa Muhammad Al-Fatih kecil. Selama ini ia menganggap bahwa dirinya dapat berbuat apa saja sekehendak hatinya lantaran ayahnya adalah seorang sultan yang sayang padanya sehingga akan selalu membelanya. Ternyata anggapannya keliru. Ia lupa bahwa ayahnya adalah seorang raja yang bijaksana dan ayah yang bertanggung jawab. Pukulan itu telah menghentak jiwanya, sekaligus menyadarkannya tentang siapa sesungguhnya dirinya. Hanya seorang anak kecil, bukan penguasa, dan yang terpenting semua peristiwa itu telah membuka hatinya untuk menerima ilmu.

Ini adalah sebuah pelajaran besar bagi keluarga Muslim hari ini. Ketika orang tua menemukan kesulitan dan keterbatasan dalam mendidik anak, maka ia harus mencari guru yang memiliki kapasitas ilmu yang mumpuni dan terpercaya untuk mendidik anaknya. Mengikhlaskan dan bertawakal kepada Allah ketika menyerahkan anaknya dengan kepercayaan penuh kepada sang guru. Bahkan ketika sang guru harus 
melakukan tindakan tegas yang tentunya sejalan dengan pendidikan Islam. Sebagaimana keikhlasan seorang Sultan Murad II ketika menyerahkan Al-Fatih kepada Syekh Ahmad untuk didik (Ashari, 2013).

Seperti telah disebutkan sebelumnya, cukup banyak problematika yang melanda negeri ini. Salah satu penyebab utamanya adalah gagalnya pendidikan Indonesia saat ini. Selain berbagai masalah pendidikan yang telah disebutkan di atas, Jaringan Pemantau Pendidikan Indonesia (JPPI) mencatat bahwa pemerintah harus segera menyelesaikan setidaknya tujuh masalah dunia pendidikan untuk dapat mewujudkan Nawacita (sembilan harapan) dalam bidang pendidikan. Tujuh permasalahan tersebut antara lain: Masih belum jelasnya kelanjutan program Wajib Belajar 12 tahun akibat belum adanya payung hukum yang dapat mendorong untuk mewujudkannya; angka putus sekolah dari jenjang SMP ke SMA mengalami kenaikan; pendidikan agama di sekolah harus segera dievaluasi dan dibenahi, baik dari metode pembelajarannya maupun gurunya; masih lemahnya pengakuan negara terhadap pendidikan pesantren dan madrasah. Padahal model pendidikan agama ini telah berperan sejak dulu, jauh sebelum Indonesia merdeka; Kartu Indonesia Pintar (KIP) harus didistribusikan dengan tepat sasaran dan waktu. Bersekolah bagi masyarakat marginal seperti masih jadi sebatas impian.

Marginal yang dimaksud terutama dialami oleh anak-anak yang berkebutuhan khusus dan warga miskin, di mana kedua kelompok tersebut mendominasi angka putus sekolah didominasi; pungutan liar dan tindak kekerasan di sekolah masih merajalela yang menjadi potret buram pendidikan di Indonesia; diskrepansi antara dunia pendidikan dengan dunia kerja. Saat ini, terdapat lebih dari tujuh juta angkatan kerja yang belum memiliki pekerjaan. Sementara di saat yang bersamaan, dunia usaha mengalami kesulitan untuk merekrut tenaga kerja terampil yang sesuai dengan kompetensi yang dibutuhkan dan siap pakai.

Tidak hanya itu, negeri ini juga seperti mengalami degradasi moral. Berdasarkan hasil catatan Transparency International Indonesia (TII) 2017 tentang Indeks Persepsi Korupsi (IPK) pada tahun 2017 yang dirilis pada Kamis (22/2/2018), dari 180 negara Indonesia menduduki peringkat ke-96 dengan nilai 37. Selain Indonesia, ada Brasil, Kolombia, Panama, Peru, Thailand, dan Zambia di peringkat dan nilai yang sama. Padahal pada tahun 2016 Indonesia memiliki nilai yang sama, yaitu 37, dengan 
menduduki peringkat ke-90. Indeks persepsi korupsi dari Transparency International menggunakan skala 0-100. Nilai 0 artinya paling korup, sedangkan nilai 100 berarti paling bersih.

Berbagai problematika di atas merupakan gambaran potret buram hasil pendidikan di negeri ini. Berdasarkan data di atas, maka diperlukan suatu kebijakan yang dapat menjadi solusi untuk menyelesaikan segala permasalahan pendidikan di negeri ini, dan cara terbaik tentu adalah belajar dari sejarah bagaimana orang-orang besar dahulu mampu menghadirkan kebesarannya di muka bumi ini. Imam Malik rahimahullah ta'ala mengatakan:

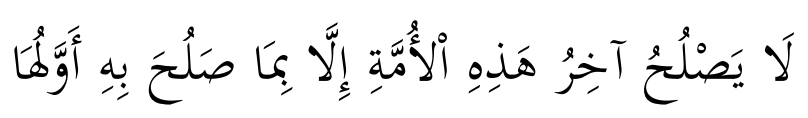

Artinya: "Generasi akhir umat ini tidak akan baik kecuali jika diperbaiki dengan sesuatu yang memperbaiki generasi awalnya."

Kebijakan-kebijakan pendidikan Harun Ar-Rasyid tentu adalah penyembuh yang sangat tepat. Ketika Ar-Rasyid sangat memuliakan ahli ilmu dan para guru dengan menggaji mereka dengan dana yang tidak sedikit (As-Sirjani, 2011), maka hal tersebut harus ditiru oleh pemangku kebijakan negeri ini agar kesejahteraan para guru dapat terjamin. Mengutamakan adab dalam pendidikan dapat menjadi solusi bagi degradasi moral di Indonesia. Rendahnya kualitas pendidikan di Indonesia menyebabkan Indonesia sama sekali tidak masuk daftar 20 negara dengan sistem pendidikan terbaik di dunia. Pada tahun 2014, posisi pendidikan di Indonesia sangatlah buruk. The Learning Curve Pearson 2014, sebuah lembaga pemeringkatan pendidikan di dunia mencatat bahwa mutu pendidikan Indonesia berada di peringkat terakhir dunia. Sedangkan tahun 2015, mutu pendidikan di Indonesia tetap saja menduduki 10 besar negara yang memiliki mutu pendidikan rendah. Jika kita mau, mutu pendidikan di Indonesia dapat ditingkatkan dengan menjadikan Al-Qur'an sebagai inti dari kurikulum, seperti apa yang diterapkan oleh Khalifah Ar-Rasyid.

Contoh nyata hasil kurikulum Qur'an adalah Al-Ma'mun, khalifah ketujuh Abbasiyah yang merupakan putra Ar-Rasyid. Hanya karena menghapal Al-Qur'an, intelektualitas dan rasa ingin tahu Al-Ma'mun bangkit (Lyons, 2013). Hal ini yang kelak membuatnya kelak menjadi pemimpin besar seperti ayahnya dan menjadi sosok yang sangat cerdas. Tidak hanya Al-Ma'mun, ilmuwan-ilmuwan lain pun lahir karena 
menjadikan Qur'an sebagai panduan. Dibangunnya Bait Al-Hikmah juga menjadi salah satu alasan jayanya pendidikan di era Abbasiyah. Bait Al-Hikmah yang tidak hanya berfungsi sebagai rumah buku tetapi juga sebagai pusat alih bahasa buku-buku pengetahuan di dunia ke dalam bahasa Arab telah melahirkan ilmuwan-ilmuwan besar. Al-Khawarizmi merupakan tokoh ilmuwan yang terbantu dengan kebijakan Ar-Rasyid ini. Ia menyusun karya besarnya, Surah Al-Aradh (Gambar/Peta Bumi) dengan mengacu pada buku Geography, karya ilmuwan Yunani, Ptolemius yang sudah dialih-bahasakan ke dalam bahasa Arab (Hitti, 2014). Apabila mutu pendidikan dan problematikaproblematika yang tengah merundung negeri ini ingin selesai, maka semua itu harus dikembalikan dengan cara Islam, sesuai hadis Nabi, “Allah akan terus menghinakan kita hingga kita kembali kepada agama."

\section{SIMPULAN DAN SARAN}

Harun Ar-Rasyid merupakan sosok khalifah yang mampu membawa Islam ke masa keemasannya dalam berbagai bidang, tak terkecuali pendidikan. Terdapat tujuh kebijakan yang diterapkan beliau dalam dunia pendidikan sebagai khalifah, antara lain memuliakan guru dan ulama, mendirikan perpustakaan, menerjemahkan buku-buku pengetahuan ke dalam bahasa Arab, menjadikan masjid sebagai pusat pendidikan, melibatkan peran orangtua dalam pendidikan, kurikulum berpusat pada Qur'an, serta mengutamakan $t a$ 'dib dalam pendidikan. Saat ini, dunia pendidikan Indonesia tengah dilanda berbagai probelematika. Di mulai dari rendahnya gaji guru, tingginya angka putus sekolah, hingga ditutup oleh rendahnya mutu pendidikan. Ketika berbicara hasil pun demikian, begitu banyak tindak inmoral yang disebabkan gagalnya pendidikan di negeri ini.

Berbagai problematika tersebut dapat diselesaikan dengan belajar dari sejarah. Sesuai perkataan Imam Malik bahwa segala hal yang merusak generasi akhir umat ini hanya bisa diperbaiki menggunakan metode umat terdahulu. Generasi terbaik umat ini adalah generasi sahabat, tabi'in, dan tabi'ut tabi'in, Harun Ar-Rasyid adalah generasi tabi'ut tabi'in. maka apabila mutu pendidikan ingin meningkat dan problematika yang tengah merundung negeri ini ingin selesai, maka semua itu harus dikembalikan dengan cara Islam, sesuai hadis Nabi, "Allah akan terus menghinakan kita hingga kita kembali kepada agama." 


\section{DAFTAR PUSTAKA}

Abdurrahman, J. (2010). "Islamic Parenting: Pendidikan Anak Metode Nabi" terjemahan Agus Suwandi. Solo: Aqwam.

Ainissyifa, H. (2014). Pendidikan Karakter dalam Perspektif Pendidikan Islam. Jurnal Pendidikan Universitas Garut, 8(1), 1-26.

Al-Khudhari, M. (2016). "Bangkit dan Runtuhnya Daulah Abbasiyah" terjemahan Masturi Ilham, Abidun Zuhri. Jakarta: Pustaka Al-Kautsar.

Amaliyah, A. (2013). Eksistensi Pendidikan Islam Di Mesir Masa Daulah Fatimiyah: Lahirnya Al-Azhar, Tokoh-tokoh Pendidikan pada Masa Daulah Fatimiyah dan Pengaruhnya terhadap Dunia Islam. Lentera Pendidikan, 16(1), 101-111.

Amin, S. M. (2010). Sejarah Peradaban Islam. Jakarta: Amzah.

An-Nawawi. (2017). Matan Hadist Arbain. Jakarta: Pustaka Ibnu Umar.

Anshori, A. A. (2015). Konsep Pemikiran Harun Ar-Rasyid dalam Pendidikan Karakter. Jurnal Penelitian, 9(2), 205-232.

As-Sirjani, R. (2011). "Sumbangan Peradaban Islam pada Dunia” terjemahan Sonif, Masturi Irham, Malik Supar (Cet. 1). Jakarta: Pustaka Al-Kautsar.

As-Suyuthi. (2015). Tarikh Khulafa. Jakarta: Pustaka As-Sunnah.

Ashari, B. (2013). Inspirasi dari Rumah Cahaya. Jakarta: Pustaka Nabawiyyah.

Budiharjo, G. T. (2013). Kebijakan Kharāj Khalifah Umar ibn Khattāb. Az Zarqa', 5(2), $115-144$.

Faidi, A. (2018). Sistem Kekhalifahan dan Konstruksi Budaya Politik Arab. Al-Ihkam, 12(1), 187-204.

Fathurrahman, A. (2018). Memahami Kebijakan Ekonomi Politik Tiga Khalifah (Sebuah Kajian Historis Tiga Fase Peradaban Islam). JES, 2(2), 156-167.

Harimurti, S. M. (2015). Seni pada Masa Pemerintahan Dinasti Abbasiyah Tahun 711 950 Masehi. Jurnal Kajian Seni, 1(2), 194-204.

Hitti, P. K. (2014). "History of the Arabs" terjemahan R. Cecep Lukman Yasin, Dedi Slamet Riyadi. Jakarta: Serambi Ilmu Semesta.

Ismiyati, N., \& Umamah, N. (2015). Peranan Harun Al-Rasyid dalam Kekhalifahan Abbasiyah Tahun 786 - 809. Artikel Ilmiah Mahasiswa, I(1), 1-12.

Israil, S. (2011). Kebijakan Ekonomi Umar Bin Khattab. Jurnal Manajemen dan Akuntansi, 12(1), 91-98.

Khairuddin. (2011). Kebijakan Politik Muawiyah. Al-Fikra: Jurnal Ilmiah KeislamanJurnal Ilmiah Keislaman, 10(1), 161-181. 
Lyons, J. (2013). "The Great Bait Al-Hikmah: Kontribusi Islam dalam Peradaban Barat” terjemahan Maufur. Jakarta: Noura Books.

Mahroes, S. (2015). Kebangkitan Pendidikan Bani Abbasiyah Perspektif Sejarah Pendidikan Islam. Jurnal Tarbiya, 1(1), 77-108.

Makrufi, A. D. (2017). The Islamic Civilization of the Abbasid Daula Period in Increasing the Interest of Reading Society (In The Digital Literacy Era). In Proceeding International Conference on Islamic Education (ICIED) "Innovations, Approaches, Challenges, and the Future" Fakultas Ilmu Tarbiyah dan Keguruan Universitas Islam Negeri (UIN) Maulana Malik Ibrahim Malang (pp. 21-28). Malang.

Maryamah. (2015). Pendidikan Islam Masa Dinasti Abbasiyah. Tadrib, 1(1).

Mubarak, F. (2009). Perkembangan Kebijakan Pendidikan Islam Indonesia. Jurnal: Ta'lim Muta'allim, 4(8), 225-242.

Nasution, A. (2017). Perkembangan Ilmu Pengetahuan pada Periode Harun Al-Rasyid dan Al-Makmun. Al-Hadi, Ii(2), 395-402.

Nurhakim, I. (2017). Kebijakan Khalifah Al-Ma' Mun tentang Pendidikan Islam. AnNidzam, 4(1), 31-42.

Purwanto, A. (2015). Ayat-ayat Semesta: Sisi-sisi Al-Qur'an yang Terlupakan. Bandung: Mizan Pustaka.

Rahmawati, L. (2008). Kebijakan Fiskal dalam Islam. Al-Qānūn, 11(2), 436-461.

Rajab, L. (2014). Filsafat Pendidikan Islam (Suatu Analisis Filosofis Pemikiran Pendidikan Islam). Biologi Sel, 3(2), 99-111.

Ridlo, A. (2013). Kebijakan Ekonomi Umar Ibn Khattab. Jurnal Al- 'Adl, 6(2), 1-28.

Salahudin. (2011). Bait Al-Hikmah dan Kontribusinya dalam Perkembangan Tradisi Keilmuan Islam pada Era Abbasiyah. Hunafa: Jurnal Studia Islamika, 8(1), 153-173.

Sari, N. (2015). Zakat Sebagai Kebijakan Fiskal pada Masa Kekhalifah Umar Bin Khattab. Jurnal Perspektif Ekonomi Darussalam, 1(2), 172-184.

Setiawan, A. (2014). Prinsip Pendidikan Karakter dalam Islam (Studi Komparasi Pemikiran Al-Ghazali dan Burhanuddin Al-Zarnuji). Dinamika Ilmu, 14(1), 112.

Setiawan, W. (2018). Reward and Punishment dalam Perspektif Pendidikan Islam. AlMurabbi, 4(2), 184-201.

Suriana. (2017). Refleksi-Introspeksi: Tantangan dan Penopang Kemajuan Lembaga Pendidikan Tinggi Islam pada Masa Dinasti Abbasiyah. Itqan, 8(2), 107-121.

Suwito. (2015). Sejarah Sosial Pendidikan Islam. Jakarta: Kencana. 
Suyuthi, A. (2011). Ta'dib sebagai Upaya Rekonstruksi Pendidikan Islam Perspektif Syed Naquib Al-Attas. Al Hikmah, 1(2), 156-169.

Syah, A. (2008). Term Tarbiyah, Ta'lim dan Ta'dib dalam Pendidikan Islam: Tinjauan dari Aspek Semantik. Al-Fikra: Jurnal Ilmiah Keislaman, 7(1).

Wahyuningsih, S. (2014). Impelementasi Sistem Pendidikan Islam pada Masa Daulah Abbasiyah dan pada Masa Sekarang. Jurnal Kependidikan, II(2), 109-126.

Wasito. (2015). Pendidikan Islam dan Peradaban Dunia dalam Kajian Daulah Abbasiyah, 26(1), 44-64.

Yanto. (2015). Sejarah Perpustakaan Bait Al-Hikmah pada Masa Keemasan Dinasti Abbasiyah. Tamaddun, XV(1), 239-258.

Yatim, B. (2016). Sejarah Peradaban Islam. Jakarta: Rajawali Pers.

Yusuf, M. (2012). Khalifah Al-Mu'tashim: Kajian Awal Mundurnya Daulah Abbasiyah. Thaqãfiyyãt, 12(1), 123-140. 